\title{
Consumption of addictive substances in mariners
}

\author{
Richard Pougnet ${ }^{1,2}$, Laurence Pougnet ${ }^{2,3}$, Brice Loddé ${ }^{1,2}$, Luisa Canals ${ }^{4}$, Sally Bell2 , \\ David Lucas ${ }^{2}$, Jean-Dominique Dewitte ${ }^{1,2}$ \\ ${ }^{1}$ Environmental, Maritime and Professional Pathologies Centre, University Hospital Morvan, Brest, France \\ ${ }^{2}$ Maritime Medicine French Society (SFMM), Brest, France \\ ${ }^{3}$ Faculty of Medicine, Val de Grâce, Paris, France \\ ${ }^{4}$ Spanish Society of Maritime Medicine (SEMM), Tarragona, Spain
}

\begin{abstract}
Background: For many years, studies have confirmed that there is a high prevalence of addiction amongst seafarers. The effect of this is even more serious when one considers their isolated and even hostile living environment presenting risks which require vigilance and rapid reactions. The purpose of this article is to determine the extent of knowledge about addiction among seafarers.

Materials and methods: This is a review of the literature between 1993 and 2013 with respect to the prevalence of consumption of alcohol, tobacco, cannabis, cocaine, heroin, and other drugs amongst seafarers. Total prevalence was calculated using the virtual population represented by the subjects of each article, when drug consumption definition was the same between articles and when mariners studied were different. Results: 63.1\% (range 38.4-96.3\%) of seafarers smoked tobacco. 14.5\% (range 8.8-75\%) of seafarers drank alcohol. 3.4\% (range 9-45\%) had used cannabis during the previous month. Few studies concerned other drugs; $3-10 \%$ of seafarers used drugs on board.

Conclusions: The prevalence of tobacco and alcohol consumption amongst seafarers was higher than that in the general population. Further studies on the use of drugs at work would be valuable for this population who are subject to significant occupational risk.
\end{abstract}

(Int Marit Health 2014; 65, 4: 199-204)

Key words: behaviour, addiction, seafarers, accidents, occupational, prevalence, alcohol, tobacco, epidemiology

\section{INTRODUCTION}

Seafarers are often represented in popular literature as heavy smokers and drinkers. Books such as Kipling's Captains Courageous, which presents a much more positive view, are rare. Clinical studies over many years have confirmed the high prevalence of addition at the heart of this population [1-4]. Many factors favour the use of drugs in seafarers: geographical remoteness, social isolation, standing by a ship, dangerous situations, stress, sleep disturbance, and also high living standards. The search for positive effects such as the stimulant effect in the fight against fatigue, or negative, as in escape from stressful situations is therefore important for seafarers. As a result, the use of drugs presents a serious public health risk. The effect on seafarers is made even more serious by their life in an isolated and hostile environment, which involves high risk and requires vigilance and rapid reactions $[5,6]$. For example, the use of alcohol or drugs is a risk factor for occupational accidents, particularly fatalities [7]. Sea fishing, for example is one of the principal industries of the United Kingdom, and is at the same time one of the most dangerous professions. Changes in working hours, extension of shifts, severe weather conditions, heavy lifting and work with hazardous equipment contributes to the raised fatality level in fishers [8]. The fatal accident rate in British fishermen was found to be 115 times higher than that of the general working population despite the progressive reduction in these levels since the second half of the 


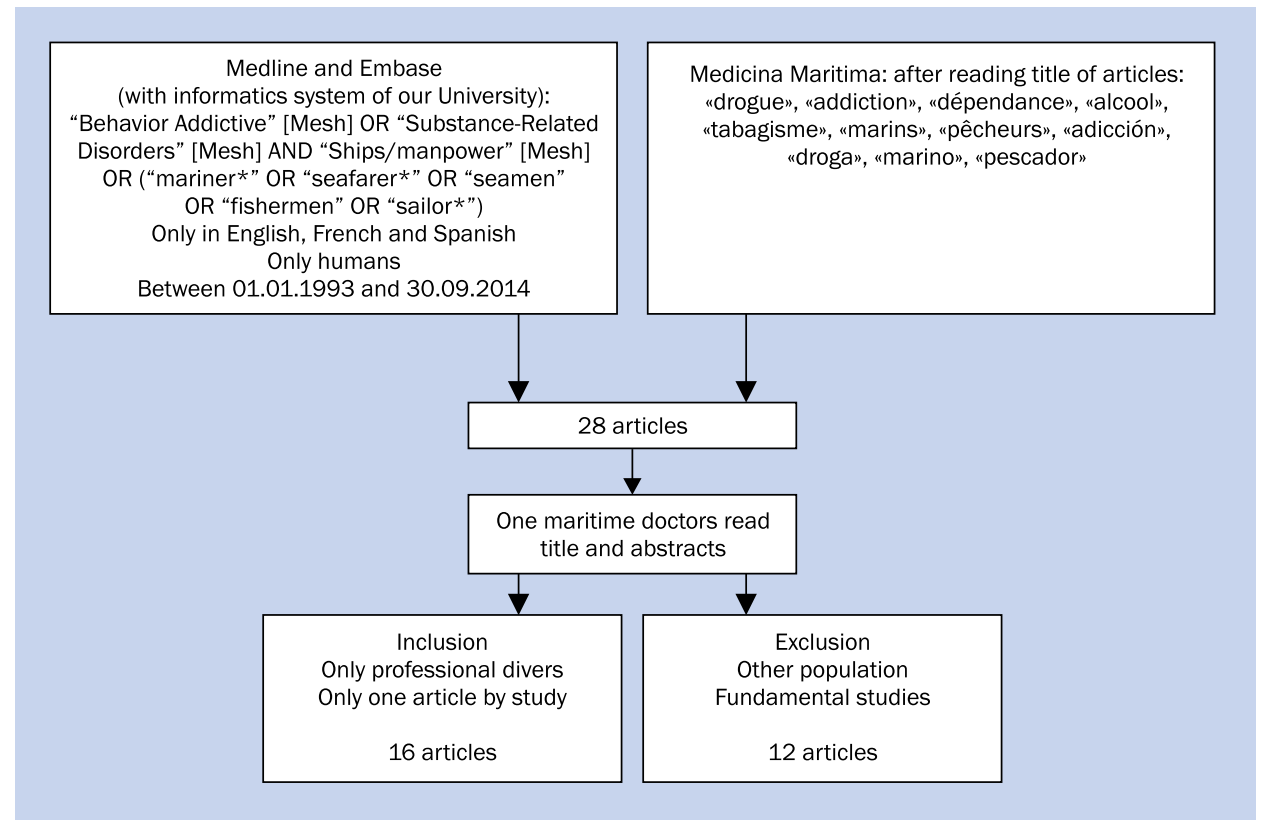

Figure 1. Flow chart

$20^{\text {th }}$ century. Recent studies show that the fishing industry is the most dangerous in the United Kingdom, and this corresponds with data from other countries [9, 10].

Alcohol consumption is one of the causes of this high fatality rate. On British flagged ships between 1939 and 2002, 1 in 100,000 seafarers died from causes linked with alcohol each year, and the rate of cirrhosis of the liver was 1.4 per 100,000 [11].

Addiction is common in seafarers, and as well as changes in general health results in increased risk of occupational accident in this population.

The aim of our work is to take stock of current knowledge about addiction among seafarers. What drugs are used and what is the prevalence of their use?

\section{MATERIALS AND METHODS}

A review of the literature was performed. Articles were sought from medical databases, Medline ${ }^{\circledR}$ and from the journal of the Spanish Society of Maritime Medicine "Medicina Maritima" (Fig. 1). Research was conducted in 3 languages: English, French and Spanish. Research in English used the keywords: "Behavior Addictive" [Mesh], "Substance-Related Disorders" [Mesh]; "Ships /manpower" [Mesh]. The words "mariner" and its synonyms were each attached to these keywords with the "AND" function. Research in French used the keywords: "drogue", "addiction", "dépendance", "alcool", "tabagisme", "marins", "pêcheurs". Research in Spanish used: "adicción", "droga", "marino", "pescador". An additional literature search was conducted from the bibliographies of each article selected. Criteria for inclusion were the study of prevalence of use of at least one drug in articles published between 01.01.1993 and 30.09.2014. Articles studying the use of drugs which did not deal specifically with seafarers were excluded. If several articles considered the same mode of consumption of a substance, total prevalence was calculated using the virtual population represented by the subjects of each article. If several articles considered the same population, these subjects were only included once.

\section{RESULTS}

\section{SELECTED ARTICLES}

Sixteen articles studying addictions amongst seafarers were selected: 15 cross-sectional descriptive studies and 1 cohort study (Table 1) [12-27]. Two studies measured urinary markers $[13,14]$.

\section{SMOKING}

The main substance used was tobacco: 40.0-96.3\% (Table 1). A recent review of the literature on cardiovascular risk factors showed a prevalence of $61.4 \%$ between 1988 and 2013 [4]. According to Mestre Molto et al. [20], alcohol consumption and smoking were strongly associated $(p=0.003)$.

\section{ALCOHOL}

Alcohol consumption was assessed differently in different articles (Table 1). Four articles used the criteria of hazardous drinking as defined by World Health Organisation (WHO). Prevalence varied 8.8-22\% (Table 1) [19, 20, 24, 25]. 


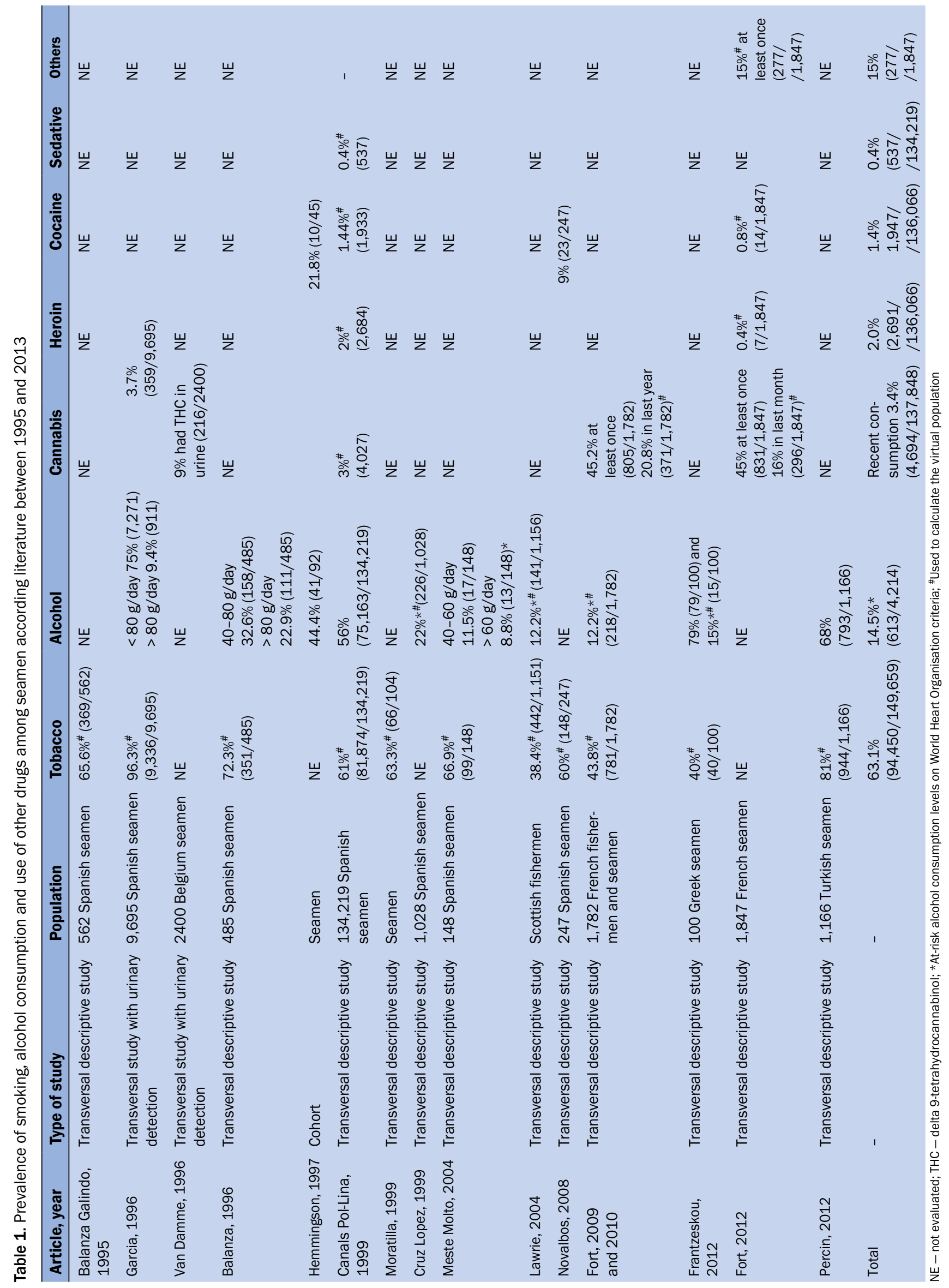


Mestre Molto et al. [20] studied consumption in 148 Spanish seafarers. Mean weekly consumption perseafarer was $168.2 \mathrm{~g}$, with $20.3 \%$ meeting the criteria for hazardous drinking. Fort et al. [24] showed that the prevalence of hazardous drinking was higher among fishermen than among merchant seamen: respectively $18.6 \%$ vs. $8 \%$ [24].

Other articles used different evaluation criteria. Balanza Galindo [12] for example showed that $22 \%$ of seafarers did not drink, $22.5 \%$ were light drinkers, $36 \%$ were moderate drinkers and $22.9 \%$ were heavy drinkers. The higher the consumption of alcohol, the higher the rate of smoking. $55.1 \%$ of non-drinkers smoked vs. $89.2 \%$ of heavy drinkers $(p>0.001)$ [12].

\section{CANNABIS}

Cannabis use was studied according to different definitions (Table 1). Fort et al. [24] showed that $45.2 \%$ of the sailors had used cannabis at least once in their lives. This prevalence was higher among merchant seamen than among fishermen: $48.1 \%$ vs. $40.5 \%$. During the previous year, $20.8 \%$ of mariners had used cannabis [24]. The prevalence of use in the previous month ranged from $3 \%$ to 16\% (Table 1) [14, 17, 23, 24].

\section{SEDATIVES AND OTHER DRUGS}

Use of these drugs is rarely studied. One study evaluated the use of sedative drugs [17], and another the use of other drugs (Table 1). Fort et al. [24] showed that 15\% of seafarers had tried a narcotic at least once in their life [23]. Hallucinogenic mushrooms, cocaine and poppers were the other main drugs used (Table 1). The prevalence of use of these other drugs in the previous month was low (1\%).

\section{CO-ADDICTION}

Canals Pol-Lina [17] studied the use of several simultaneous drugs uses. $73 \%$ of the seafarers had used a drug at some point in their life. $90 \%$ of these involved alcohol and tobacco. A link was found between the use of cannabis and other drugs: cocaine $(r=0.94)$, sedatives $(r=0.91)$, alcohol $(r=0.77)$, heroin $(r=0.71)$. Alcohol use was not defined in this study.

\section{DRUG USE ON BOARD}

Several studies considered the use of drugs on board. Percin et al. [27] showed that $68 \%$ of fishers used alcohol, but only $10 \%$ used it on board a ship whilst fishing. $81 \%$ of fishermen smoked on board, two thirds smoking more than 20 a day and $72 \%$ smoking more often on board than ashore [27]. Novalbos et al. [22] found that $9 \%$ of fishers used illegal drugs, of whom $3 \%$ used drugs on board. $30 \%$ of fishermen drank alcohol on board, at an average of $8.5 \mathrm{~g} /$ day.

\section{TOTAL PREVALENCE}

In the studies using the same definitions of consumption, total prevalence was calculated. The main substances used were: tobacco (63.1\%), alcohol (14.5\%) and cannabis (3.3\%) (Table 1).

\section{DISCUSSION}

This literature review was used to assess the prevalence of addiction in seafarers according to international publications: $63.1 \%$ smoked, $14.5 \%$ were hazardous drinkers according to the WHO definition and $3.4 \%$ had used cannabis in the previous month. Few studies focused on the use of heroin, cocaine, sedatives or other drugs. The use of alcohol or drugs on board a ship was also infrequently studies. However, $10 \%$ of mariners (or more) consume alcohol on board.

The aim of this study was to select articles from multiple databases in several languages. This is particularly important, since the issue of addiction amongst seafarers is an international problem.

On the same boat, mariners come from several countries and a mariner travels around the world. The method of calculation of total prevalence may appear biased. In calculating virtual populations from these studies, one seafarer may be counted several times. This possibility was taken into account, and given the years of the studies and the country of origin of the studies the probability that a seafarer was included several times is small. Equally analysis showed that the definitions of usage varied between studies, so in calculating total prevalence, the size of some virtual populations was small.

This literature review showed a high prevalence of smoking. Seafarers smoked more than the general populations of France and the United States: $63.1 \%$ vs. $21.5 \%$ and $20.6 \%$, respectively [28-30]. Several reasons may contribute to these findings, such as unusual work patterns and lack of sleep [31]. Tobacco may be used as a stimulant, a distraction in those who are bored or as an anxiolytic for those in a stressful environment [32-34].

The prevalence of alcohol consumption was also higher than in the general population. By comparison, in France, problem drinking is seen in $10 \%$ of the population [35]. Nonetheless, studies in seafarers define the different levels of consumption of alcohol. It would be interesting to define the prevalence according to the different levels of use: use, use at-risk, harmful use, dependence. In order to understand the high prevalence in seafarers, several parameters should be studied. As an example, seafarers are at high risk of accident, of being victims of piracy, or of loss at sea [7, 36]. All of these may precipitate post traumatic stress disorder, which may lead to increased alcohol consumption [37-39]. In general, seafarers are exposed to many risk factors for 
stress, which is in itself a risk factor for drugs dependence $[34,40,41]$. In the general population, mortality due to alcohol consumption is a significant proportion of total mortality, particularly when one considers premature deaths [42]. This mortality is even more important amongst seafarers for whom alcohol is a risk factor.

The use of alcohol on board ranged between 10\% and $30 \%$ according to studies $[22,27]$. This use at work would seem to be higher than in the general population. Indeed, in a study of 2,805 employees, Frone [42] showed that the use of alcohol in the workplace was $15 \%$ in the United States. The effects of this use were not studied in mariners. These parameters allow a better assessment of the risk of occupational accidents. Meanwhile, Novalbos et al. [22] showed that $3 \%$ of the mariners used illegal drugs on board, which is comparable with data from the general population [22-43].

The consumption of drug on board is always a danger to seafarers. The risk of serious injury is often reported in the literature $[44,45]$. Thus, the high prevalence of drug consumption and severity of accidents make this problem a major issue of maritime health. Clear information for seafarers should be their issue worldwide, as well as possibility to be cured in an addiction medical centre. But prevention would be more effective if it were issued to seafarers before they begin to use these drugs.

\section{CONCLUSIONS}

The prevalences of smoking and alcohol use were higher for mariners than for the general population. The use of cannabis in previous month was 3.3\%. Other drugs were not enough studied in this population. In particular, it would be useful to better assess drug use at work for this population exposed to significant occupational risks.

\section{REFERENCES}

1. Brun-Gulbrandsen S, Irgens-Jensen 0. Abuse of alcohol among seamen. Br J Addict Alcohol Other Drugs 1967; 62: 19-27.

2. Nitka J. Selected medical and social factors and alcohol drinking in Polish seafarers. Bull Inst Marit Trop Med Gdynia 1990; 41: 53-57.

3. Filikowski J, Renke W, Rzepiak M. Observations on the conditions of work of Polish seafarers and their health. Bull Inst Marit Trop Med Gdynia 1992; 43: 13-17.

4. Pougnet R, Pougnet L, Loddé B, Canals-Pol ML, Jegaden D, Lucas D, Dewitte JD. Cardiovascular risk factors in seamen and fishermen: review of literature. Int Marit Health 2013; 64:107-113.

5. Anger J-P. Principaux effets psychiques des stupéfiants: risques en milieu professionnel. Annales de Toxicologie Analytique 2002; 14: 68-73.

6. Matos A, Sanchez de la Nieta FJ, Escamilla FL et al. Detección de drogas de abuso en la Armada. Hábitos tóxicos como iesgos laborales en el trabajo a bordo. Su prevención. Medicina Maritima 1999; 1: 417-423.

7. Shapovalov KA. Traumatism with fatal outcome in maritime workers. Bull Inst Marit Trop Med Gdynia 1992; 43: 57-60.
8. Matheson C, Morrison S, Murphy E, Lawrie T, Ritchie L, Bond C. The health of fishermen in the catching sector of the fishing industry: a gap analysis. Occup Med (Lond) 2001; 51: 305-311.

9. Hansen HL, Pedersen G. Influence of occupational accidents and deaths related to lifestyle on mortality among merchant seafarers. Int J Epidemiol 1996; 25: 1237-1243.

10. Roberts SE. Britain's most hazardous occupation: commercial fishing. Accid Anal Prev 2010; 42: 44-49.

11. Roberts SE. Work related mortality from gastrointestinal diseases and alcohol among seafarers employed in British merchant shipping from 1939 to 2002. Int Marit Health 2005; 56: 29-47.

12. Balanza Galindo S, Mestre Moltó F. [Cardiovascular risk factors in the fishing environment of Cartagena and Castellon]. Rev Esp Salud Publica 1995; 69: 295-303.

13. Garcia MJ, Ro Rosillo A, Montez Martinez A. Consumo de opiaceos en marineros de la Ria de Pontevedra. Medicina Maritima 1997; 1: $205-216$.

14. Van Damme J. Problems of alcohol- and drug abuse amongst seafarers. Searching for a wider approach. Bull Inst Marit Trop Med Gdynia 1996; 47: 53-60.

15. Balanza Galindo G. [Consumo de alcohol y factores de riesgo cardiovascular en una poblacion laboral maritima]. Medicina Maritima 1996; 1: 16-23.

16. Hemmingsson T, Lundberg I, Romelsjö A, Alfredsson L. Alcoholism in social classes and occupations in Sweden. Int J Epidemiol 1997; 26: 584-591.

17. Canals Pol-Lina ML. [Registro de un factor de riesgo a través del econocimiento médico laboral preceptivo para embarque en España: el uso de sustancias adictivas]. Medicina Maritima 1999; 1: 407-415.

18. Moratilla G. [Estudio de hábitos tóxicos y de riesgo cardiovascular en buceadores Profesionales]. Medicina Maritima 1997; 1: 70-77.

19. Cruz López M, Lazuen AA, Minguez F, Bolado HA, Costa AM, Novalbos Ruiz JP. [Estudio del consumo de alcohol en marinos de la provincia de Cádiz]. Medicina Maritima 1999; 1: 273-278.

20. Mestre Moltó F, Balanza Galindo S, Fenollosa Tamarit MD. [Consumo del alcohol en una población de pescadores de bajura. Factores sociolaborales y biológicos asociados]. Medicina Maritima 2004; 4: $25-34$.

21. Lawrie T, Matheson C, Ritchie L, Murphy E, Bond C. The health and lifestyle of Scottish fishermen: a need for health promotion. Health Educ Res 2004; 19: 373-379.

22. Novalbos J, Nogueroles P, Soriguer M, Piniella F. Occupational health in the Andalusian Fisheries Sector. Occup Med (Lond) 2008; 58: 141-143.

23. Fort E, Massardier-Pilonchery A, Bergeret A. Alcohol and nicotine dependence in French seafarers. Int Marit Health 2009; 60: 18-28.

24. Fort E, Massardier-Pilonchéry A, Bergeret A. Psychoactive substances consumption in French fishermen and merchant seamen. Int Arch Occup Environ Health 2010; 83: 497-509.

25. Frantzeskou E, Kastania AN, Riza E, Jensen OC, Linos A. Risk factors for fishermen's health and safety in Greece. Int Marit Health 2012; 63: 155-161.

26. Fort E, Massardier-Pilonchéry A, Facy F, Bergeret A. Prevalence of drug use in French seamen. Addict Behav 2012; 37: 335-338.

27. Percin F, Akyol O, Davas A, Saygi H. Occupational health of Turkish Aegean small-scale fishermen. Occup Med (Lond) 2012; 62: 148-151.

28. Asplund K, Bonita R, Kuulasmaa K et al. Multinational comparisons of stroke epidemiology. Evaluation of case ascertainment in the WHO MONICA Stroke Study. World Health Organization Monitoring Trends and Determinants in Cardiovascular Disease. Stroke 1995; 26: 355-360. 
29. Asfar T, Ebbert JO, Klesges RC, Relyea GE. Do smoking reduction interventions promote cessation in smokers not ready to quit? Addict Behav 2011; 36: 764-768.

30. CDC. Cigarette smoking among adults and trends in smoking cessation: United States, 2008. MMWR Morbidity and Mortality Weekly Report 2009; 58: 1227-1232.

31. Hystad SW, Saus ER, S trevik B, Eid J. Fatigue in seafarers working in the offshore oil and gas re-supply industry: effects of safety climate, psychosocial work environment and shift arrangement. Int Marit Health 2013; 64: 72-79.

32. Kingdom SE, Smith AP. Combined effects of work-related stress in Her Majesty's Coastguard (HMCG). Int Marit Health 2012; 63: 63-70.

33. Carotenuto A, Molino I, Fasanaro A, Amenta F. Psychological stress in seafarers: a review. Int Marit Health 2012;63(4):188-94.

34. Lodde B, Jegaden D, Lucas D, Feraud M, Eusen Y, Dewitte JD. Stress in seamen and non seamen employed by the same company. Int Marit Health 2008; 59: 53-60.

35. http://sfalcoologie.asso.fr/download/3_donneesepidemiologiques_sfa2009.pdf.

36. Low A. Seafarers and passengers who disappear without a trace from aboard ships. Int Marit Health 2006; 57: 219-229.
37. Stewart SH. Alcohol abuse in individuals exposed to trauma: a critical review. Psychol Bull 1996; 120: 83-112.

38. Cerdá M, Tracy M, Galea S. A prospective population based study of changes in alcohol use and binge drinking after a mass traumatic event. Drug Alcohol Depend 2011; 115: 1-8.

39. Schroeder J, Polusny M. Risk factors for adolescent alcohol use following a natural disaster. Prehosp Disaster Med 2004; 19: 122-127.

40. Nielsen MB, Bergheim K, Eid J. Relationships between work environment factors and workers' well-being in the maritime industry. Int Marit Health 2013; 64: 80-88.

41. Turner RJ, Lloyd DA. Cumulative adversity and drug dependence in young adults: racial/ethnic contrasts. Addiction 2003; 98: 305-315.

42. Frone MR. Prevalence and distribution of alcohol use and impairment in the workplace: a U.S. national survey. J Stud Alcohol 2006; 67: 147-156.

43. Frone MR. Prevalence and distribution of illicit drug use in the workforce and in the workplace: findings and implications from a U.S. national survey. J Appl Psychol 2006; 91: 856-869.

44. Shapovalov KA. Injuries of the floating crew of the Northern water pool in a state of alcoholic intoxication. Int Marit Health 2013; 64: 41-50.

45. Dahl E, Ulven A, Horneland AM. Crew accidents reported during 3 years on a cruise ship. Int Marit Health 2008; 59: 19-33. 